\title{
Lower energy and pulse stacking. A safer alternative for skin tightening using fractional $\mathrm{CO}_{2} \operatorname{laser}^{1}$
}

\author{
Marcos Matias Motta ${ }^{\mathrm{I}}$, Rafael Fantelli Stelini ${ }^{\mathrm{II}}$, Davi Reis Calderoni ${ }^{\mathrm{III}}$, Rovilson Gilioli ${ }^{\mathrm{IV}}$, Paulo Kharmandayan ${ }^{\mathrm{V}}$
}

DOI: http://dx.doi.org/10.1590/S0102-865020160010000005

${ }^{I}$ Fellow Master degree, Postgraduate Program in Surgical Sciences, Faculty of Medical Sciences, Universidade de Campinas (UNICAMP), Brazil. Intellectual and scientific content of the study, design the protocol, surgical procedures, acquisition and interpretation of data, statistical analysis, manuscript writing.

${ }^{I}$ MD, Department of Anatomic Pathology, Faculty of Medical Sciences, UNICAMP, Campinas-SP, Brazil. Intellectual and scientific content of the study, design the protocol, acquisition and interpretation of data, statistical analysis, critical revision.

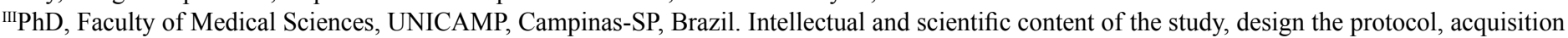
and interpretation of data, statistical analysis, critical revision.

${ }^{\text {Iv }} \mathrm{PhD}$, Molecular Biology and Genetics. Head, Multidisciplinary Center for Biological Investigation on Laboratory Animals Science, UNICAMP, Campinas-SP, Brazil. Surgical procedures, acquisition of data.

vAssociate Professor, Head, Division of Plastic Surgery, Faculty of Medical Sciences, UNICAMP, Campinas-SP, Brazil. Intellectual and scientific content of the study, design the protocol, surgical procedures, interpretation of data, manuscript writing, critical revision.

\begin{abstract}
PURPOSE: To evaluate the effect of different energies and stacking in skin shrinkage. METHODS: Three decreasing settings of a fractional CO2 laser were applied to the abdomen of Twenty five Wistar rats divided into three groups. Group I $(n=5)$ was histologically evaluated for microthermal zones dimensions. Groups II and III $(\mathrm{n}=10$ each) were macroscopic evaluated with freeware ImageJ for area contraction immediately and after 30 and 60 days. RESULTS: Nostatistical significancewas foundwithinmicrothermalzonehistologicaldimensions(GroupI)inallsettings studied.(Ablation depth: 76.90 to $97.18 \mu \mathrm{m}$; Coagulation depth: 186.01 to $219.84 \mu \mathrm{m})$. In Group II, macroscopic evaluation showed that all settings cause significantimmediateskin contraction. Thehighestsetting cause significantmore intense tightening effectinitially, contracting skin area from 258.65 to $179.09 \mathrm{~mm}^{2}$. The same pattern was observed in Group III. At 30 and 60 days, the lowest setting significantly sustained contraction. CONCLUSION: Lower fractional $\mathrm{CO}_{2}$ laser energies associated to pulse stacking could cause consistent and long lasting tissue contraction in rats.
\end{abstract}

Key words: Lasers, Gas. Skin Aging. Laser Therapy. Rats. 


\section{Introduction}

Treatment of photo aging with $\mathrm{CO}_{2}$ laser resurfacing had been considered the gold standard for decades ${ }^{1,2}$. However, although having very impressive results, it was nearly abandoned by doctors and patients over time due to its prolonged recovery time and high rate of complications. Among these complications stand out hypertrophic scars and dyschromia. With the concept of fractional photothermolysis ${ }^{2,3}$, treating photo aging with $\mathrm{CO}_{2}$ fractional laser became popular in recent years due to its potential to deliver consistent results coupled with shorter recovery time and low complication rates.

In fractional mode $\mathrm{CO}_{2}$ laser creates an array of micro treatment zones in the epidermis and dermis surrounded by healthy tissue. This has been considered to be responsible for the significant shorter recovery time ${ }^{4}$. Histological evaluation showed that an increase in pulse duration results in a proportional increase in lesion depth ${ }^{5}$. Another study demonstrated that a higher penetration into the dermis causes a greater clinical efficacy in skin texture and rhytides ${ }^{6}$.

Complications from this modality are generally mild, temporary and easily managed. A retrospective study evaluating 490 treatments in 374 patients demonstrated an overall incidence of adverse effects of $13.6 \% \%^{7}$. The most frequent were acneiform eruption $(5,3 \%)$, bacterial infection $(2.2 \%)$, hyperpigmentation $(1.2 \%)$ and prolonged erythema $(0.8 \%)$. Although infrequent and lower than in traditional $\mathrm{CO}_{2}$, they do exist and should be prevented whenever possible.

A study comparing three different decreasing fluencies for treating photo aging, showed very similar results for the two lower fluencies compared to the highest one, in terms of biological response. Lower fluencies decrease the risk of scarring ${ }^{8}$.

Another way of getting deeper in the dermis is the use of multiple overlapping pulses (stacking) ${ }^{9,10}$. Few histological studies describe the association between the applied parameters and the dimensions of the microthermal zones (MTZ) as well as the use of stacking for increasing their depth. One experimental study found a linear correlation between the depth of ablation and the energy used $^{11}$.

A feature of treatment with $\mathrm{CO}_{2}$ laser is the immediate contraction of the tissue, and in traditional non-fractional $\mathrm{CO}_{2}$ laser resurfacing this is well known ${ }^{12,13}$. It was not possible to find in the literature an objective evaluation of the shrinkage of the skin after application of fractional $\mathrm{CO}_{2}$ laser, despite this fact is clinically observable.

Besides that, the use of lighter settings to achieve that skin contraction has not been addressed yet. We investigate if it is possible to achieve consistent tissue contraction with lower settings in association with pulse stacking.

\section{Methods}

The board of Ethical Committee of Animal Research approved the study, under the protocol number 3012-1.

Twenty-five male Wistar rats aging ten weeks were included in the study. They had free access to water and standard laboratory chow $(3.100 \mathrm{kcal} / \mathrm{kg})$ and they were kept on a 12-hour light/dark cycle. The room temperature was kept between 23 and $24^{\circ} \mathrm{C}$.

\section{Laser procedure}

The animals were anaesthetized with an intra-peritoneal injection of $80 \mathrm{mg} / \mathrm{kg}$ ketamine plus $10 \mathrm{mg} / \mathrm{kg}$ xylazine and positioned on dorsal decubitus. Their abdomens were shaved and stamped with four $15 \times 15 \mathrm{~mm}$ squares. Then, the vertices of each square were tattooed for later area identification (Figure 1). In addition, an identification sequential number was tattooed on each animal's tail.

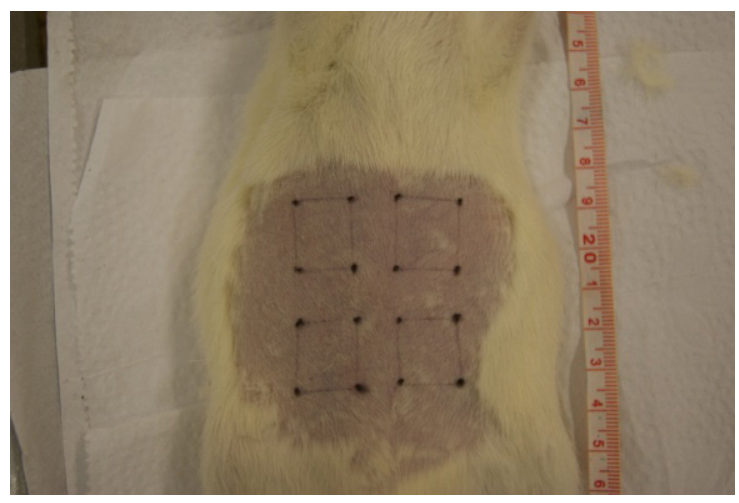

FIGURE 1 - Treatment areas on animal's abdomen.

Each square was assigned a number as shown in Figure 2. Each treatment area (except control area - area 1) underwent single-pass treatment with $\mathrm{CO}_{2}$ laser equipped with a scanner specially developed for fractional skin resurfacing (Smartxide Dot; DEKA, M.E.L.A., Florence, Italy). 


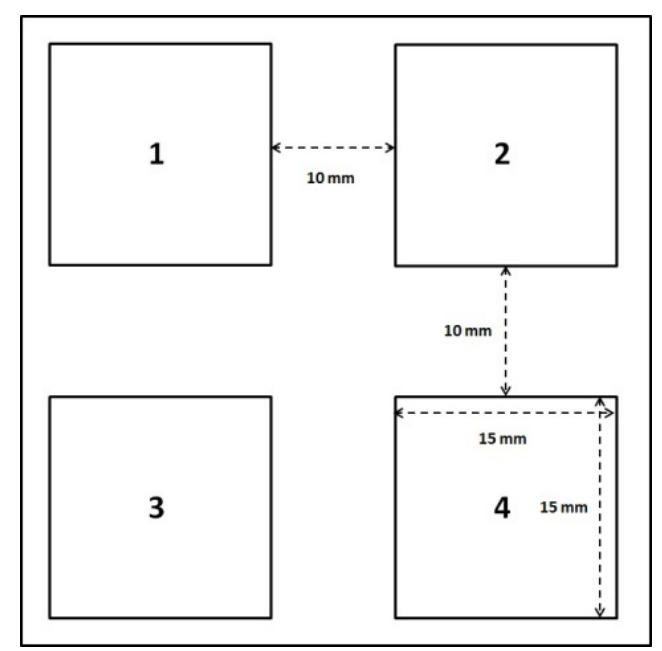

FIGURE 2 - Treatment areas: dimensions and arrangement.

The employed variable laser parameters (power, exposure time, stacking, fluence and energy per each MTZ) are summarized in Table 1. Other parameters were kept the same for all treated areas (500- $\mu \mathrm{m}$ spacing and $120-\mu \mathrm{m}$ spot size).

TABLE 1 - Laser settings for each area.

\begin{tabular}{cccccc}
\hline & Power & $\begin{array}{c}\text { Exposure } \\
\text { Time }\end{array}$ & Stack & Fluence & $\begin{array}{c}\text { Energy/ } \\
\text { MTZ }\end{array}$ \\
\hline Area 1 & - & - & - & - & - \\
Area 2 & $30 \mathrm{~W}$ & $900 \mu \mathrm{s}$ & 1 & $3.74 \mathrm{~J} / \mathrm{cm} 2$ & $27 \mathrm{~mJ}$ \\
Area 3 & $20 \mathrm{~W}$ & $300 \mu \mathrm{s}$ & 3 & $2.49 \mathrm{~J} / \mathrm{cm} 2$ & $18 \mathrm{~mJ}$ \\
Area 4 & $10 \mathrm{~W}$ & $300 \mu \mathrm{s}$ & 3 & $1.87 \mathrm{~J} / \mathrm{cm} 2$ & $13.5 \mathrm{~mJ}$ \\
\hline
\end{tabular}

\section{Groups for analysis}

The twenty-five animals were distributed into three groups.

Group I ( $\mathrm{n}=5)$ was euthanized by anesthesia overdose immediately after laser treatment. Treatment areas were collected for histological evaluation of laser channel's (MTZ) dimensions.

Group II $(n=10)$ was euthanized 30 days after the procedure, and group III $(n=10)$ was euthanized 60 days after the procedure. The same euthanasia method was used. Both groups II and III were macroscopically analyzed for contraction patterns. In these groups, no MTZ evaluation was carried out because at these time points it is impossible to identify them.

\section{Histological analysis}

Tissue specimens from group I animals were fixed in $10 \%$ buffered formalin then embedded in paraffin. Then, a vertically cut 5-10 $\mu \mathrm{m}$ slice was obtained from the center of each treatment area and stained with hematoxylin and eosin (H\&E). A calibrated microscope DM500 (Leica Microsystems, Wetzlar, Germany) equipped with a digital camera ICC 50HD (Leica Microsystems, Wetzlar, Germany) was used for image capture. Laser MTZ dimensions were measured using calibrated Leica Application Suite (LAS) Version 4.1.0 (Leica Microsystems, Wetzlar, Germany).

The entire slide was scanned for each sample. The three deepest MTZ found were considered for analysis, as they should approximately represent the MTZ central axis. Each of these three MTZ were recorded and for each one the following parameters were quantified: ablation depth, coagulation depth and coagulation width (measured at the surface).

Following these linear measurements, also a volume estimation of MTZ using a cone shape model previously described by Skovbølling et al. ${ }^{10}$, was calculated.

\section{Macroscopic analysis}

Standardized color photographs using a digital camera Alpha 230 (Sony) were obtained from all animals from groups II and III immediately before and after laser treatment as well as before the animal's sacrifice. Image analysis was carried out with freeware ImageJ (National Institutes of Health, USA. http://www. imagej.nih.gov/ij) for area calculation of each square.

Treatment areas from groups II and III were statistically analyzed in two distinct ways: evaluating each area's behavior along time points and evaluating all areas together at each time point compared to the control area.

\section{Statistics}

Origin $^{\circledR}$ software was used for statistical analysis. In order to compare the evaluated parameters it was used ANOVA for repeated measures. Variables studied were ablation depth, coagulation depth, surface damage width, MTZ volume and area of laser application. They were converted into ranks due to lack of normal distribution. The level of significance used in this study was $5 \%$. 


\section{Results}

Group I-Histological analysis of MTZ

\section{Ablation depth}

It is shown in Table 2. We found no statistical significance between areas.

TABLE 2 - Ablation depth results for each region.

\begin{tabular}{cccc}
\hline Region & Settings & $\begin{array}{c}\text { Ablation Depth - } \\
\text { Median }\end{array}$ & Range \\
\hline 1 & No treatment & - & - \\
2 & $27 \mathrm{~mJ}-$ single & $89.08 \mu \mathrm{m}$ & $56-98 \mu \mathrm{m}$ \\
& pulse of $900 \mu \mathrm{s}$ & & \\
3 & $18 \mathrm{~mJ}-3$ stacked & $97.18 \mu \mathrm{m}$ & $80-118 \mu \mathrm{m}$ \\
& $\begin{array}{c}\text { pulses of } 300 \mu \mathrm{s} \\
4\end{array}$ & & \\
& $\begin{array}{c}13.5 \mathrm{~mJ}-3 \text { stacked } \\
\text { pulses of } 300 \mu \mathrm{s}\end{array}$ & $76.90 \mu \mathrm{m}$ & $75-120 \mu \mathrm{m}$ \\
\hline
\end{tabular}

\section{Coagulation depth}

A coagulation zone surrounded the ablation area, and its depth showed a decreasing pattern as the energy was reduced as shown in Table 3. No statistical significance was found.

TABLE 3 - Coagulation depth results for each region.

\begin{tabular}{cccc}
\hline Region & Settings & $\begin{array}{c}\text { Coagulation } \\
\text { Depth - Median }\end{array}$ & Range \\
\hline 1 & No treatment & - & - \\
2 & $27 \mathrm{~mJ}-$ single & $219.84 \mu \mathrm{m}$ & $127-241 \mu \mathrm{m}$ \\
& pulse of $900 \mu \mathrm{s}$ & & \\
3 & $18 \mathrm{~mJ}-3$ stacked & $210.47 \mu \mathrm{m}$ & $166-274 \mu \mathrm{m}$ \\
& pulses of $300 \mu \mathrm{s}$ & & \\
4 & $13.5 \mathrm{~mJ}-3$ & $186.01 \mu \mathrm{m}$ & $185-219 \mu \mathrm{m}$ \\
& stacked pulses of & & \\
\hline
\end{tabular}

\section{Surface damage width}

This included ablation width plus the surrounding coagulation zone at the epidermis. Results are demonstrated in Table 4. No level of significance was found between areas.
TABLE 4 - Surface damage width results for each region

\begin{tabular}{cccc}
\hline Region & Settings & $\begin{array}{c}\text { Surface damage } \\
\text { width - Median }\end{array}$ & Range \\
\hline 1 & No treatment & - & - \\
2 & $27 \mathrm{~mJ}-$ single & $412,33 \mu \mathrm{m}$ & $305-450 \mu \mathrm{m}$ \\
& pulse of $900 \mu \mathrm{s}$ & & \\
3 & $18 \mathrm{~mJ}-3$ stacked & $430.70 \mu \mathrm{m}$ & $273-581 \mu \mathrm{m}$ \\
& pulses of $300 \mu \mathrm{s}$ & & \\
4 & $13.5 \mathrm{~mJ}-3$ & $406.14 \mu \mathrm{m}$ & $372-454 \mu \mathrm{m}$ \\
& stacked pulses of & & \\
\hline
\end{tabular}

\section{$\underline{\text { MTZ volume }}$}

We calculated MTZ volume using the cone volume formula (cone shape model) and the results are shown in Table 5. Again, there was no statistical significance.

TABLE 5 - Microthermal zones (MTZ) Volume for each region.

\begin{tabular}{cccc}
\hline Region & Settings & $\begin{array}{c}\text { MTZ volume - } \\
\text { Median }\end{array}$ & Range \\
\hline 1 & No treatment & - & - \\
2 & $27 \mathrm{~mJ}-$ single \\
pulse of $900 \mu \mathrm{s}$ & $8.48 \times 10^{-3} \mathrm{~mm}^{3}$ & $4-13 \times 10^{-3} \mathrm{~mm}^{3}$ \\
3 & $18 \mathrm{~mJ}-3$ & $11.2 \times 10^{-3} \mathrm{~mm}^{3}$ & $7-14 \times 10^{-3} \mathrm{~mm}^{3}$ \\
& stacked pulses & & \\
of $300 \mu \mathrm{s}$ & & \\
4 & $13.5 \mathrm{~mJ}-3$ & $8.62 \times 10^{-3} \mathrm{~mm}^{3}$ & $6-10 \times 10^{-3} \mathrm{~mm}^{3}$ \\
& stacked pulses \\
of $300 \mu \mathrm{s}$ & & \\
\hline
\end{tabular}

Group II - Macroscopic analysis - 30 days

Before treatment, there was no statistically difference between all areas.

When following each area along time points, it was observed that immediately after treatment all areas except the control (area 1) were significantly smaller than before laser shot. Thirty days after the procedure, area 1 (control) was larger than it was before the experiment $(\mathrm{p}=0.001)$. Areas 2 and 3 showed no significant difference to pre-treatment dimensions. On the other hand, area 4 was smaller than before treatment $(p=0.029)$ (Figure 3). 


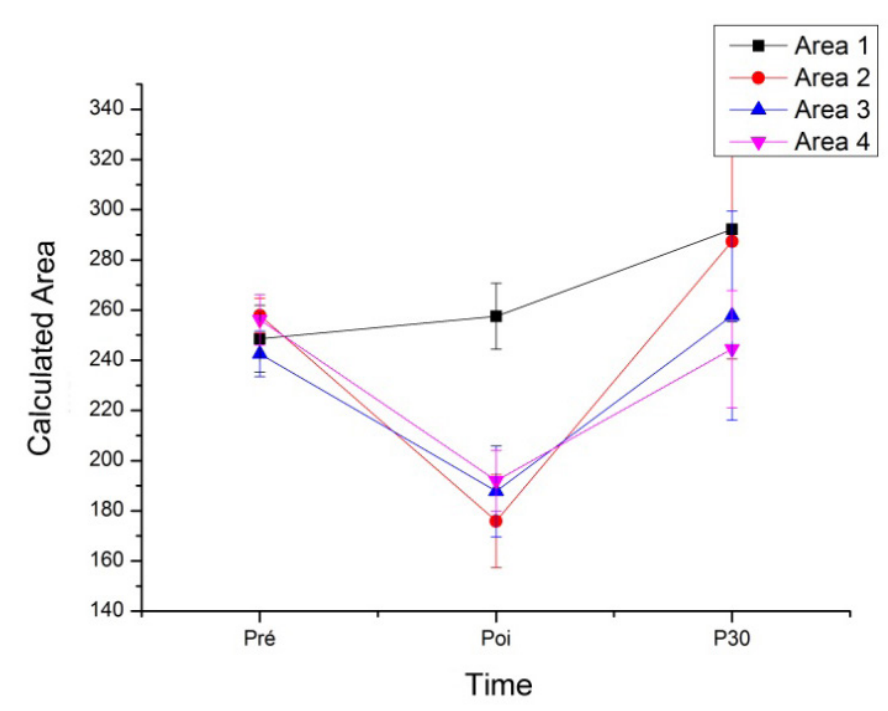

FIGURE 3 - Group II: Linear dimensions x Time points.

Analyzing areas together at each time point demonstrated that immediately after laser, all treatment areas were significantly smaller than the control area. In addition, area 2 was smaller than area $3(p=0.029)$ and area $4(p=0.017)$. After thirty days, area 4 was significantly smaller than area $1(\mathrm{p}=0.0001)$ and area $2(\mathrm{p}=0.004)$, and was the only area that remained smaller than the observed in the pre-treatment period (Table 6).

TABLE 6 - Calculated linear dimensions for Group II.

\begin{tabular}{cccc}
\hline Region & Pre-Treatment & $\begin{array}{c}\text { Immediately } \\
\text { after }\end{array}$ & 30 days after \\
\hline $\mathbf{1}$ & $249.58 \mathrm{~mm}^{2}$ & $262.87 \mathrm{~mm}^{2}$ & $291.99 \mathrm{~mm}^{2}$ \\
$\mathbf{2}$ & $258.65 \mathrm{~mm}^{2}$ & $179.09 \mathrm{~mm}^{2}$ & $296.92 \mathrm{~mm}^{2}$ \\
$\mathbf{3}$ & $242.92 \mathrm{~mm}^{2}$ & $179.89 \mathrm{~mm}^{2}$ & $254.83 \mathrm{~mm}^{2}$ \\
$\mathbf{4}$ & $258.05 \mathrm{~mm}^{2}$ & $190.81 \mathrm{~mm}^{2}$ & $243.49 \mathrm{~mm}^{2}$ \\
\hline
\end{tabular}

Another way of evaluating the contraction effect, was measuring the variation in size of each area from immediately post treatment to day 30 .

In group II we observed that after being treated with the laser all areas had a positive variation, that is, all areas increased in size after thirty days. However, area 2 had a significant higher increase than area $1(\mathrm{p}<0.0001)$, area $3(\mathrm{p}=0.005)$ and area 4 $(\mathrm{p}<0.0001)$ (Figure 4).

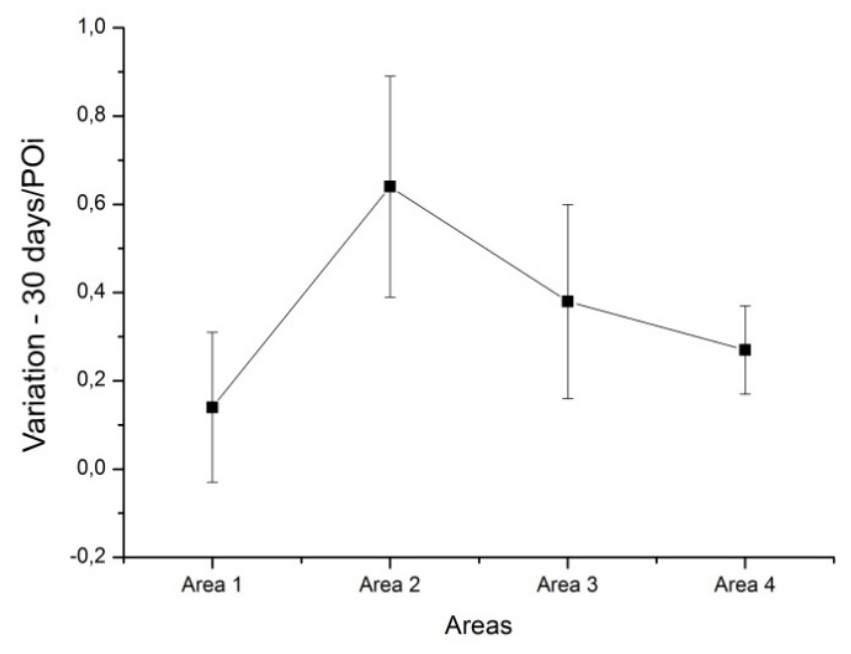

FIGURE 4 - Linear dimensions variation from immediately after laser to 30 days after.

\section{Group III - Macroscopic analysis - 60 days}

Treatment areas were statistically analyzed the same way as group II.

When following each area along time points, it was observed that immediately after treatment all areas except the control (area 1) were significantly smaller. Sixty days after the procedure, control area $(\mathrm{p}=0.0001)$, area $2(\mathrm{p}=0.003)$ and area 3 $(p=0.025)$ were larger than they were before the experiment. On the other hand, area 4 was still smaller than it was before treatment, but without statistical significance. We can observe this behavior in Figure 5.

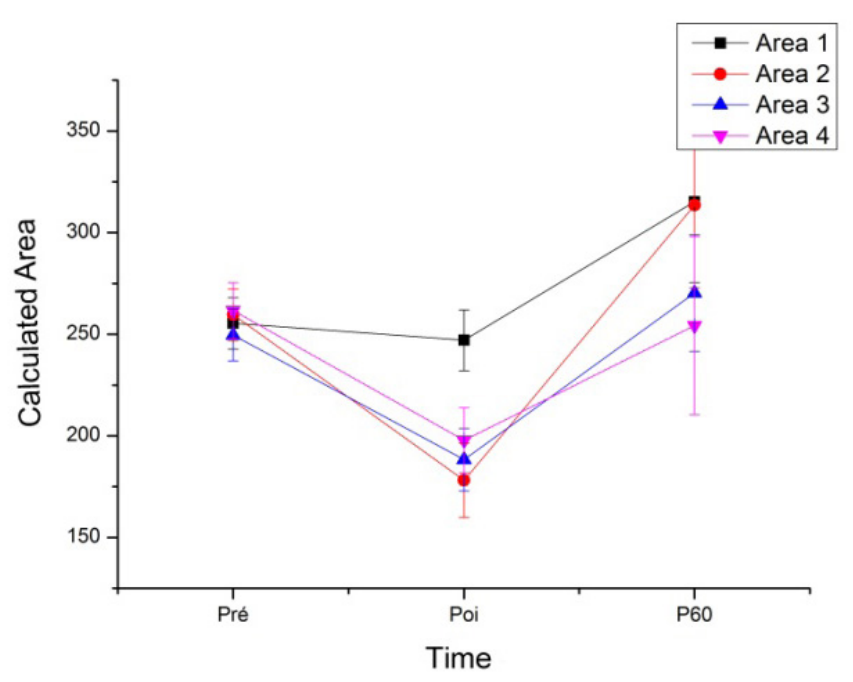

FIGURE 5 - Group III: Linear dimensions x Time points. 
Analyzing areas together at each time point demonstrated that immediately after laser, all treatment areas were significantly smaller than the control area. In addition, area 2 was significantly smaller than area $4(\mathrm{p}=0.001)$. After sixty days, area 4 was significantly smaller than area $1(\mathrm{p}=0.030)$ and area $2(\mathrm{p}=0.008)$ (Table 7).

TABLE 7 - Calculated linear dimensions for Group III.

\begin{tabular}{cccc}
\hline Region & Pre-Treatment & $\begin{array}{c}\text { Immediately } \\
\text { after }\end{array}$ & 60 days after \\
\hline $\mathbf{1}$ & $256.63 \mathrm{~mm}^{2}$ & $246.05 \mathrm{~mm}^{2}$ & $323.52 \mathrm{~mm}^{2}$ \\
$\mathbf{2}$ & $256.95 \mathrm{~mm}^{2}$ & $179.61 \mathrm{~mm}^{2}$ & $307.75 \mathrm{~mm}^{2}$ \\
$\mathbf{3}$ & $247.59 \mathrm{~mm}^{2}$ & $191.17 \mathrm{~mm}^{2}$ & $267.78 \mathrm{~mm}^{2}$ \\
$\mathbf{4}$ & $261.18 \mathrm{~mm}^{2}$ & $198.19 \mathrm{~mm}^{2}$ & $256.43 \mathrm{~mm}^{2}$ \\
\hline
\end{tabular}

Measuring the variation in size of each area from immediately post treatment to day 60 showed that area 2 had a significantly greater variation than area $1(p<0.0001)$ and area 4 $(p=0.001)$. Its variation was also greater than area 3 , but without statistical significance. In addition, area 4 was not significantly different from the control (area 1). We can observe these results in Figure 6.

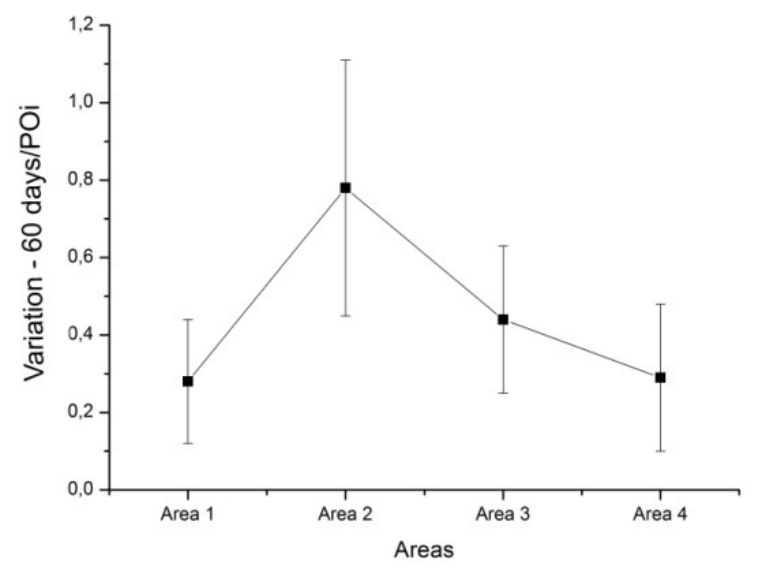

FIGURE 6 - Linear dimensions variation from immediately after laser to 60 days after.

\section{Discussion}

The pursuit of good results in treating photo aging and other disorders with fractional $\mathrm{CO}_{2}$ laser has been studied widely in recent years ${ }^{14-16}$. Since the papers of Hantash et al. ${ }^{1,2}$ which demonstrated fractional photothermolysis concept applied to the
$\mathrm{CO}_{2}$ laser, this modality has virtually replaced traditional $\mathrm{CO}_{2}$ laser resurfacing. Another study ${ }^{17}$ demonstrated that molecular pathways, in both traditional and fractional $\mathrm{CO}_{2}$ laser wound healing, are very similar. Since that, it was possible to treat photo aging without a high incidence of dyschromia and hypertrophic scaring.

In the fractional modality, an array of microthermal zones (MTZ) is created within the epidermis and dermis. These MTZ's consist of a central ablation area surrounded by a thin annular area of coagulated tissue. Ross et al. ${ }^{18}$, although studying traditional $\mathrm{CO}_{2}$ laser, had already discussed the importance of coagulation zone in tissue contraction. In between each MTZ there is healthy tissue, which is said to be responsible for the faster recovery time ${ }^{4}$.

This column pattern allows fractional $\mathrm{CO}_{2}$ laser to reach deeper areas into the dermis than traditional $\mathrm{CO}_{2}$ laser. Saluja et $a l .{ }^{6}$ demonstrated that a deeper coagulation results in better clinical efficacy in skin texture and rhytides. Also, a persistent collagen remodeling for at least three months after treatment was immunohistochemically demonstrated in humans when deep dermis was reached ${ }^{2}$. Another study ${ }^{5}$, demonstrated in ten patients that lesion depth was proportional to increases in pulse duration.

Increasing depth is also possible by means of overlapping pulses at the same site (stacking). Oni et al..$^{10}$ demonstrated that a $15 \mathrm{~mJ}$ double pulse resulted in similar MTZ as a single $30 \mathrm{~mJ}$ pulse. In this article, they also suggest that double pulsing could result in improved outcomes, as the amount of unaffected tissue between MTZ is reduced. This would increase dermal injury leading to increased collagen synthesis.

Few histological studies describe the relationship between laser settings and MTZ dimensions, as well as the use of stacked pulses. Besides that, there are many different devices, which are difficult to compare. One study used an ex vivo porcine model to characterize laser columns at different energy settings with a constant pulse length in single and stacked pulses ${ }^{11}$. In this study, they found a linear correlation between ablation depth and energy. Column diameter was not related to energy levels, and coagulation zone thickness increased until $16 \mathrm{~mJ}$ only.

In our study, we found no significant difference between the three settings studied in terms of ablation depth, coagulation depth, superficial tissue damage, and calculated cone-shaped MTZ volume. These findings are very interesting especially when thinking about the MTZ calculated volume. This represents the amount of tissue that is actually injured by the laser and will lead to collagen synthesis ${ }^{10}$. After reducing the power in 33,3\% (from area two to area three) and splitting the $900 \mu \mathrm{s}$ exposure time 
into three $300 \mu$ s stacked pulses (resulting in a $33.3 \%$ decrease in fluence and energy), we found a $32 \%$ increase on the MTZ volume. Even when power was reduced by $66.6 \%$ (from area two to area four) and the $900 \mu$ s exposure time was again split into three $300 \mu \mathrm{s}$ stacked pulses (which resulted in a 50\% reduction in fluence and energy) the results showed an increase of $1 \%$ on MTZ volume.

Although no statistical significance was found, these results could indicate that is possible to achieve similar amounts of tissue damage into the dermis with less aggressive power settings and with the use of pulse stacking. A technical limitation affecting these data is the difficulty in obtaining the MTZ real central axis on histology ${ }^{1,11}$. Even a minor angling during technical procedures may result in a non-real central axis. Zelickson et al. ${ }^{19}$ proposed a computational method for calculating MTZ depth based on horizontal sectioning. On their work, they found slightly larger MTZ comparing to traditional vertical sectioning. We tried to minimize these limitations by scanning every MTZ on each slide for the three deepest ones and averaging them.

Another point that interferes in MTZ dimension is hair distribution on the animal's abdomen. On histology we identified different patterns of skin appendages and dermis thickness comparing the upper skin abdominal specimens (areas one and two) with the lower ones (areas three and four. This could partially explain the fact that area two, although receiving the highest power with a single pulse, showed the smallest MTZ values. On their work, Oni et al. ${ }^{10}$ described in humans that a higher skin content of hair follicles, as well as blood vessels and sebaceous glands, absorbs part of the laser energy. The same study ${ }^{10}$ also propose that using double pulsing the ablative column could continue beyond these structures due to less absorption within them. In single pulse modality the ablative column is usually terminated when there is an appendage in its path.

Another study comparing facial and abdominal skin ${ }^{20}$ found that MTZ were shallower in the face due to the higher water content of skin appendages. In our study, areas receiving stacked pulses (areas three and four) showed similar ablation depth values to area two, which received a single pulse although with a higher power.

Tissue contraction after traditional $\mathrm{CO}_{2}$ laser resurfacing is well known. Ross et al demonstrated in an experimental study, with traditional $\mathrm{CO}_{2}$ laser resurfacing, that immediate contraction and residual thermal damage have a linear correlation to increasingly number of passes when using lower fluences ${ }^{12}$.

In fractional $\mathrm{CO}_{2}$ laser resurfacing, this tissue shrinkage also occurs and is related to the radial micro-contraction of multiple MTZs. This was observed both in ex-vivo and in-vivo studies ${ }^{1,2}$.
Our study evaluated tissue contraction after fractional $\mathrm{CO}_{2}$ laser both immediately after and at thirty and sixty days post procedure. To accomplish this purpose we used freeware ImageJ for area calculation, which has been successfully used in previous studies $^{21,22}$.

Immediately after laser treatment we observed that area two, which received higher fluence and energy within a single pulse, contracted significantly more than areas three and four in group II and significantly more than area four in group III. This is in agreement with Hantash et al. ${ }^{1}$ who in their first study on characterization of a fractional $\mathrm{CO}_{2}$ laser device, they hypothesized that with a constant treatment density, pulse energy would predict tissue shrinkage. The same correlation between higher energies and immediate tissue tightening was found in clinical studies ${ }^{5,23}$.

On the other hand, when examining tightening effect at days thirty and sixty we noticed that although the animals grew, areas three and four were smaller than area two. That is, although showing a greater tightening effect just after treatment, the area receiving the highest energy apparently lost most of that effect after thirty to sixty days. In fact, this area approximated area one dimensions, which received no treatment. We hypothesized that the higher energy extrapolated the modulating and suppressing balance in would healing response as suggested by Yuan et al. ${ }^{24}$. Thus, instead of stimulating neo-colagenogenesis and tissue contraction, higher energies would impair it.

This objective experimental analysis suggests that it is not necessary to use higher energies to obtain consistent skin tightening. Some clinical studies had similar results. A randomized split-face trial in Asians ${ }^{24}$ treating acne scars, showed no difference in clinical outcomes after using $10 \mathrm{~mJ}$ or $20 \mathrm{~mJ}$ at fixed densities. Prignano et al. ${ }^{8}$ in a clinical study using the same equipment as the one used in the present study, found that there is no advantage of using a higher fluence. They compared fluences at 2.07, 2.77 and $4.14 \mathrm{~J} / \mathrm{cm}^{2}$ and both histological and clinical data demonstrated the lower fluences had very similar responses. With the fluence at $4.14 \mathrm{~J} / \mathrm{cm}^{2}$, besides the lack of clinical advantage, histology demonstrated a larger amount of collagen fibers, which could represent more risks of scarring. In this way, it may possible to improve clinical results with lower energy and the use of pulse stacking.

\section{Conclusion}

Lower fractional $\mathrm{CO}_{2}$ laser energies associated to pulse stacking could cause consistent and long lasting skin shrinkage in rats. 


\section{References}

1. Hantash BM, Bedi VP, Chan KF, Zachary CB. Ex vivo histological characterization of a novel ablative fractional resurfacing device. Lasers Surg Med. 2007;39(2):87-95. doi: 10.1002/1sm.20405.

2. Hantash BM, Bedi VP, Kapadia B, Zakia Rahman Z ,Jiang K, Tanner H, Chan KF, Zachary CB. In vivo histological evaluation of a novel ablative fractional resurfacing device. Lasers Surg Med. 2007;39(2):96-107.doi: 10.1002/lsm.20468.

3. Manstein D, Herron GS, Sink RK, Tanner H, Anderson RR. Fractional photothermolysis: a new concept for cutaneous remodeling using microscopic patterns of thermal injury. Lasers Surg Med. 2004;34(5):426-38. doi: 10.1002/1sm.20048.

4. Prignano F, Campolmi P, Bonan P, Ricceri F, Cannarozzo G, Troiano $\mathrm{M}$, Lotti T. Fractional $\mathrm{CO}_{2}$ laser: a novel therapeutic device upon photobiomodulation of tissue remodeling and cytokine pathway of tissue repair. Dermatol Ther. 2009;22 Suppl 1:S8-15. doi: 10.1111/j.1529-8019.2009.01265.x.

5. Tierney EP, Hanke CW, Petersen J. Ablative fractionated $\mathrm{CO}_{2}$ laser treatment of photoaging: a clinical and histologic study. Dermatol Surg. 2012;38(11):1777-89. doi: $10.1111 / \mathrm{j} .1524$ 4725.2012.02572.x.

6. Saluja R, Khoury J, Detwiler SP, Goldman MP. Histologic and clinical response to varying density settings with a fractionally scanned carbon dioxide laser. J Drugs Dermatol. 2009;8(1):17-20. PMID: 19180891

7. Shamsaldeen O, Peterson JD, Goldman MP. The adverse events of deep fractional $\mathrm{CO}(2)$ : a retrospective study of 490 treatments in 374 patients. Lasers Surg Med. 2011;43(6):453-6. doi: 10.1002/ 1sm.21079.

8. Prignano F, Bonciani D, Campolmi P, Cannarozzo G, Bonan P, Lotti T. A study of fractional $\mathrm{CO}_{2}$ laser resurfacing: the best fluences through a clinical, histological, and ultrastructural evaluation. J Cosmet Dermatol. 2011;10(3):210-6. doi: 10.1111/j.14732165.2011.00571.x

9. Fitzpatrick RE, Smith SR, Sriprachya-anunt S. Depth of vaporization and the effect of pulse stacking with a high-energy, pulsed carbon dioxide laser. J Am Acad Dermatol. 1999;40(4):615-22. PMID: 10188684.

10. Oni G, Robbins D, Bailey S, Brown SA, Kenkel JM. An in vivo histopathological comparison of single and double pulsed modes of a fractionated CO(2) laser. Lasers in Surg Med. 2012;44(1):4-10. doi: $10.1002 / 1 \mathrm{sm} .21150$.

11. Skovbølling Haak C, Illes $M$, Paasch U, Hædersdal $M$ Histological evaluation of vertical laser channels from ablative fractional resurfacing: an ex vivo pig skin model. Lasers Med Sci. 2011;26(4):465-71. doi: 10.1007/s10103-010-0829-2.

12. Ross EV, Yashar SS, Naseef GS, Barnette DJ, Skrobal M, Grevelink $\mathrm{J}$, Anderson RR. A pilot study of in vivo immediate tissue contraction with $\mathrm{CO} 2$ skin laser resurfacing in a live farm pig. Dermatol Surg. 1999;25(11):851-6. PMID: 10594596

13. Seckel BR, Younai S, Wang KK. Skin tightening effects of the ultrapulse CO2 laser. Plast Reconstr Surg. 1998;102(3):872-7. PMID: 9727458.

14. Gold MH, Biron JA. Combined superficial \& deep fractional skin treatment for photodamaged skin--a prospective clinical trial. J Cosmet Laser Ther. 2012;14(3):124-32. doi: 10.3109/14764172.2012.670708.

15. Tretti Clementoni M, Galimberti M, Tourlaki A, Catenacci M, Lavagno R, Bencini PL. Random fractional ultrapulsed $\mathrm{CO}_{2}$ resurfacing of photodamaged facial skin: long-term evaluation. Lasers Med Sci. 2013;28(2):643-50. doi: 10.1007/s10103-0121116-1.
16. Ozog DM, Liu A, Chaffins ML, Ormsby AH, Fincher EF, Chipps LK, Mi QS, Grossman PH, Pui JC, Moy RL. Evaluation of clinical results, histological architecture, and collagen expression following treatment of mature burn scars with a fractional carbon dioxide laser. JAMA Dermatol. 2013;149(1):50-7. doi: 10.1001/2013. jamadermatol.668.

17. Reilly MJ, Cohen M, Hokugo A, Keller GS. Molecular effects of fractional carbon dioxide laser resurfacing on photodamaged human skin. Arch Facial Plast Surg. 2010;12(5):321-5. doi: 10.1001/ archfacial.2010.38.

18. Ross EV, McKinlay JR, Anderson RR. Why does carbon dioxide resurfacing work? A review. Arch Dermatol. 1999;135(4):444-54. PMID: 10206052.

19. Zelickson BD, Walgrave SE, Al-Arashi MY, Altshuler GB, Yaroslavsky IV, Childs JJ, Cohen RH, Erofeev AV, Depina EF, Smirnov MZ, Kist DA, Tabatadze DR. Semi-Automated method of analysis of horizontal histological sections of skin for objective evaluation of fractional devices. Lasers Surg Med. 2009;41(9):63442. doi: 10.1002/1sm.20843.

20. Bailey SH, Brown SA, Kim Y, Oni G, Abtahi F, Richardson JA, Hoopman J, Barton F, Kenkel JM. An intra-individual quantitative assessment of acute laser injury patterns in facial versus abdominal skin. Lasers Surg Med. 2011;43(2):99-107. doi: 10.1002/1sm.21015.

21. Cai Z, Vallis KA, Reilly RM. Computational analysis of the number, area and density of gamma-H2AX foci in breast cancer cells exposed to (111)In-DTPA-hEGF or gamma-rays using Image-J software. Int J Radiat Biol. 2009;85(3):262-71. doi: 10.1080/09553000902748757.

22. Sun Z, Wang Y, Ji S, Wang K, Zhao Y. Computer-aided analysis with Image $\mathrm{J}$ for quantitatively assessing psoriatic lesion area. Skin Res Technol. 2015;21(4):437-43. doi: 10.1111/srt.12211.

23. Rahman Z, MacFalls H, Jiang K, Chan KF, Kelly K, Tournas J, Stumpp OF, Bedi V, Zachary C. Fractional deep dermal ablation induces tissue tightening. Lasers Surg Med. 2009;41(2):78-86. doi: 10.1002/1sm.20715.

24. Yuan XH, Zhong SX, Li SS. Comparison study of fractional carbon dioxide laser resurfacing using different fluences and densities for acne scars in Asians: a randomized split-face trial. Dermatol Surg. 2014;40(5):545-52. doi: 10.1111/dsu.12467.

\section{Correspondence:}

Prof. Dr. Paulo Kharmandayan

Rua Tessália Vieira de Camargo, 126

Cidade Universitária "Zeferino Vaz"

Caixa Postal: 6111 13083-887 Campinas - SP Brasil

Tels.: (55 11)95020-2080 / (55 19)3521-7092

Fax: (55 19)3521-8043

pkharmand@hotmail.com

Received: Sept 22, 2015

Review: Nov 18, 2015

Accepted: Dec 23, 2015

Conflict of interest: none

Financial source: none

${ }^{1}$ Research performed at Multidisciplinary Center for Biological Investigation, Laboratory Animals Science and Division of Plastic Surgery, Department of Surgery, Faculty of Medical Sciences, Universidade de Campinas (UNICAMP), Brazil. 